\title{
Studies on Fishing Depth and Difference in Catch by Color of Jigs for Purpleback Flying Squid Symplectoteuthis oualaniensis and Luminous Flying Squid Eucleoteuthis luminosa*1
}

\author{
Hiroshi Kobayashi*2 and Yuichiro Yamaguchi*3 \\ (Received July 29, 1987)
}

\begin{abstract}
Symplectoeuthis oualaniensis and Eucleoteuthis luminosa were caught with hand-lines under fish attracting light, and a study was made to investigate the depth of catching, water temperature and the relationship between the catch and the color of Jigs. The following results were obtained.

1. At each fishing area, a large number of $S$. oualaniensis was caught above the thermocline (high temperature zone), their catch zone was shallower than that for $E$. luminosa. On the other hand, E. luminosa appeared to be caught in a large number in the deeper zone, within the thermocline (low temperature zone). This fact seems to indicate that rather than the brightness in water, the vertical distribution of the water temperature, is greatly related to the difference of the swimming zone (catch zone) of the two species.

2. The chi-squares test was applied to the number of squids by jigs of various colors (red, white and green). The results supported a hypothesis that the catch of squids is independent of the color of a jig. The results are thought to indicate that squids do not have such a good sense of color.
\end{abstract}

Squids are generally seen in the mid-layer in the day time (Eucleoteuthis luminosa*4 has been taken in water of less than $1300 \mathrm{~m}$ in depth $\left.{ }^{11}\right)$ and come near to the surface at night to feed. This is the daily rhythmic habit of squids. In squid jiging fishery, squids in the surface zone are the subject of angling. Squids are gathered by fish attracting lamps, and they are caught by hand-lining and automatic angling. It is thought to be a very important factor to know the swimming zone of squids under attracting lamp for efficient use of these fishing gears. In such fishing techniques, jigs are used in many cases. Fishermen are strongly fond of using colored jigs since it is thought to be largely related to the catch of squids. Thus, it is desirable to test which type of jig is most effective for various squids. There is a wide variety of jigs in many colors and shapes, some being prepared by fishermen of long experience and other being from jig manufactures. There have been reports about behavior of squids under the attracting lamp ${ }^{2)}$ and fishing results used jigs of various colors or shapes. ${ }^{3}$ However, there are very few reports which studied the relationship between colors of a jig and feeding behavior of squids, that is, the catch of squids.

This study deals with the relationship among the catch of Symplectoteuthis oualaniensis ${ }^{* 5}$ and $E$. luminosa, swimming depth of squids, water temperature and color of a jig under fish attracting lamp, based on the fishing test using hand lines for $S$. oualaniensis and $E$. luminosa. The fishing test was conducted by the Seisuimaru, a training ship of the Faculty of Bioresources, Mie University.

\section{Materials}

The data used in the present study were the results of fishing of $S$. oualaniensis and E. luminosa caught by $5 \sim 8$ anglers during cruises of $86-\mathrm{R}-4$ (May), 86-R-10 (Oct.) and 86-R-11 (Oct. Nov.) by the Seisuimaru. The fishing areas were Kumanonada, Murotooki and Hyuganada, which are shown in Fig. 1. The number of squids caught in those three fishing areas was 242 for $S$. oualaniensis and 350 for E. luminosa. Table 1 shows the details of the angling tests. Fig. 2 shows the mantle length frequency $S$. oualaniensis and $E$. luminosa which were angling.

*1 The outline of this report was presented in part at meeting Jap. Soc. Sci. Fish. Tokyo, April 1987.

*2 Faculty of Bioresources, Mie University, Edobashi Tsu 514, Japan (小林 裕: 三重大学生物资源学部).

*3 Yamagata Chikuma Nagano, 390-13, Japan (山口裕一郎：辰野買山形村).

* Sujiika in Japanese.

*5 Tobiika in Japanese. 

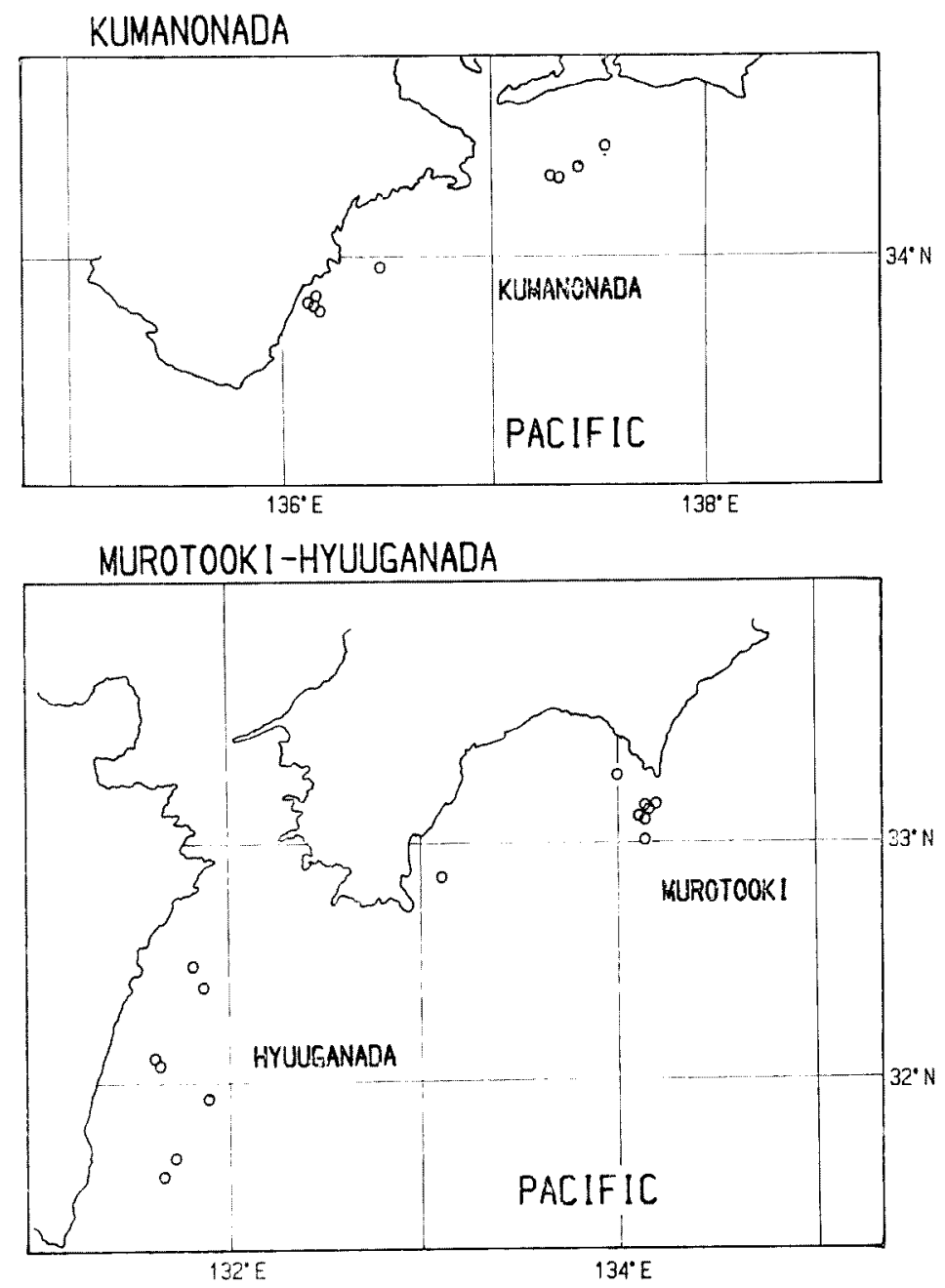

Fig. 1. Maps of the test fishing area and the fishing positions (O).

\section{Methods}

\section{Records of the Catch}

The anglers recorded the following items:

The color of the jigs used, the actual length of the fishing line paid out, the angle of the fishing line at the time of catching, the species name of squids caught, and the angling site on deck.

\section{Fishing Gear}

Fig. 3 shows the setup of the fishing gear used. The fishing gear consisted of lighted jig as a sinker at the free end of line, five coiled cloth-shaded jigs of the same color attached at $70 \mathrm{~cm}$ interval and a small lamp (1.5V) above the last jig. Since the gear was utilized for hand-angling, the length of line was limited and the depth of the jigs was also limited to $80 \sim 90 \mathrm{~m}$.

\section{Method of Squid Luring}

No particular fishing lamps were used, but all the lights for illuminating the deck and all the lights for working were switch on during fishing (Fig. 4).

\section{Water Temperature of Fishing Areas}

The data of the water temperature were taken from the MBT observations which were performed each time fishing test was carried out.

\section{Measurement of Light Quantum in the Sea}

The value of the light quantum in the sea was measured using a light quantum meter (LI-1000).

\section{Results and Discussicn}

\section{Measurement of Depth of Jig}

The depth of the jig $(Y)$ was measured by the 
Table 1. Results of the tests fishing by areas

\begin{tabular}{|c|c|c|c|c|c|}
\hline \multirow{2}{*}{ Date } & \multirow{2}{*}{ L. age } & \multicolumn{2}{|c|}{ Catches } & \multirow{2}{*}{$\mathbf{N}$} & \multirow{2}{*}{ Operation time } \\
\hline & & \multicolumn{2}{|c|}{ Kumanonada } & & \\
\hline May 20 & 11.1 & 12 & 0 & 7 & $20: 00 \sim 23: 00$ \\
\hline 21 & 12.1 & 9 & 0 & 7 & $20: 00 \sim 23: 00$ \\
\hline 22 & 13.1 & 99 & 0 & 7 & $20: 00 \sim 23: 00$ \\
\hline 23 & 14.1 & 113 & 0 & 5 & $20: 00 \sim 23: 00$ \\
\hline Oct. 14 & 10.2 & 18 & 11 & 6 & $20: 00 \sim 23: 00$ \\
\hline 15 & 11.2 & 35 & 4 & 6 & $20: 00 \sim 23: 00$ \\
\hline 16 & 12.2 & 12 & 1 & 6 & $20: 00 \sim 23: 00$ \\
\hline 18 & 14.2 & 8 & 0 & 5 & $20: 00 \sim 22: 00$ \\
\hline 25 & 21.2 & 36 & 0 & 7 & $21: 00 \sim 23: 40$ \\
\hline \multicolumn{6}{|c|}{ Murotooki } \\
\hline Oct. 26 & 22.2 & 0 & 0 & 8 & $20: 30 \sim 22: 30$ \\
\hline 27 & 23.2 & 4 & 14 & 8 & \\
\hline 28 & 24.2 & 0 & 38 & 7 & $20: 00 \sim 23: 00$ \\
\hline 29 & 25.2 & 2 & 8 & 7 & $20: 00 \sim 22: 30$ \\
\hline 31 & 27.2 & 0 & 19 & 7 & $18: 30 \sim 21: 15$ \\
\hline \multicolumn{6}{|c|}{ Hyuuganada } \\
\hline Nov. 4 & 1.7 & 0 & 53 & 7 & $18: 30 \sim 21: 15$ \\
\hline 5 & 2.7 & 0 & 44 & 7 & $18: 30 \sim 21: 05$ \\
\hline 6 & 3.7 & 0 & 11 & 7 & $18: 30 \sim 20: 30$ \\
\hline 7 & 4.7 & 0 & 6 & 6 & $18: 30 \sim$ \\
\hline 8 & 5.7 & 0 & 30 & 6 & $18: 30 \sim$ \\
\hline 12 & 9.7 & 2 & 0 & 6 & $18: 30 \sim$ \\
\hline 14 & 11.7 & 0 & 1 & 8 & $18: 30 \sim$ \\
\hline 15 & 12.7 & 0 & 2 & 8 & $18: 30 \sim$ \\
\hline
\end{tabular}

Sp. 1: Eucleoteuthis luminosa, Sp. 2: Symplectoteuthis oualamiensis, N: Number of angler, L. age: Lunner age.

following methods: one being measured by chemical tube and other being a mathematical method. The latter, a calculated depth $(X)$ was obtained by multiplying the length of the fishing line $(L)$ with a cosine of the angle $(A)$ between the fishing line and out side plate of ship. A regression equation, $Y=1.14 X-0.73$, was obtained between the two measured depth. The measured depth is a somewhat larger than the calculated one. The correlation coefficient obtained was as high as 0.94 . The results described above make it clear that the fishing line forms nearly straight line during fishing. The depth of squids caught by the jigs was determined in the following method, immediately after the angler felt a bitting signal from swimming squids, the angle $(A)$ was measured and the depth was determined from Fig. 5.

\section{Results of Measurement of Light Quantum}

Fig. 4 shows the position of the illumination lights (mercury vapor lamp) equipped for the Seisuimaru watt of bulb, angling sites and the measuring sites of light quantum. Nine $1000 \mathrm{~W}$ lights are fitted irregularly along the starboard of the ship. Table 2 shows the value of light quantum $\left(19.5 \mu \mathrm{E} / \mathrm{S} / \mathrm{m}^{2}=1 \mathrm{k} 1 \mathrm{x}\right)$ measured at a height of $2 \mathrm{~m}$ above the water surface. Due to irregularly equipped superstructures of the ship and irregular arrangement of light, the number of light quantum differed from site to site.

Table 3 shows the underwater measurement of the number of light quantum in water, which were measured at site number 6 using a $1000 \mathrm{~W}$ light at a height of $3.5 \mathrm{~m}$ above the sea surface, together with the measurements at the same site at day time. The transparency of water was $20 \mathrm{~m}$ in two measurement. It is said that, during clear full moon night, the illumination intensity at the sea surface perpendicular to the moon is $0.41 \mathrm{x}$. It is also said that a $1 \mathrm{kw}$ incandescent lamp placed just above the sea level gives an illumination intensity of $100 \mathrm{~lx}$ at about $4 \mathrm{~m}$ below the sea level, $10 \mathrm{~lx}$ at $8 \mathrm{~m}, 1 \mathrm{~lx}$ at $15 \mathrm{~m}$ and $0.1 \mathrm{~lx}$ at $26 \mathrm{~m}$. It has been reported that the minimum illumination intensity required for luring fishes is $0.01 \mathrm{~lx}^{4}{ }^{4}$ ) Judging from the fact stated above, it may be clear that useing illumination light alone had sufficient effect in attracting the two species of 


\section{Species 1 (KUMANONADA) SPRING}

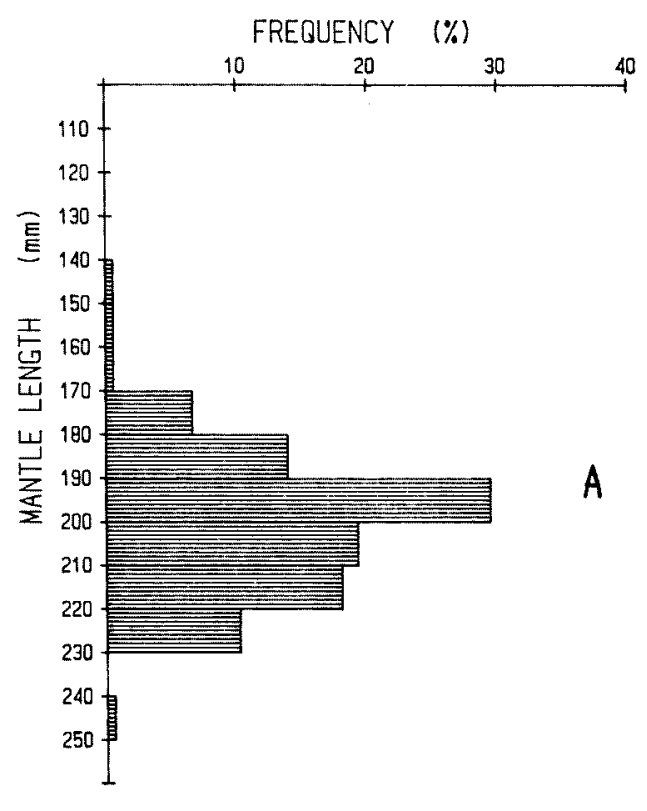

\section{Species 2 (MUROTOOKI) AUTUMN}

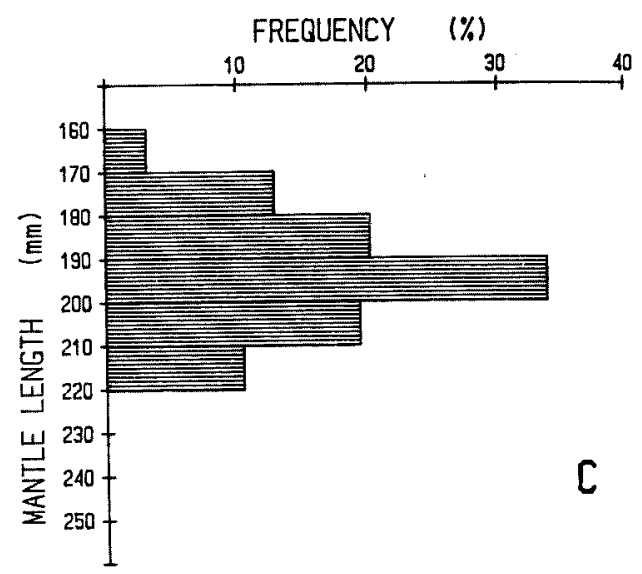

Species 1 (KUMANONADA) AUTUMN

\section{Species 2 (HYUUGANADA) AUTUMN}
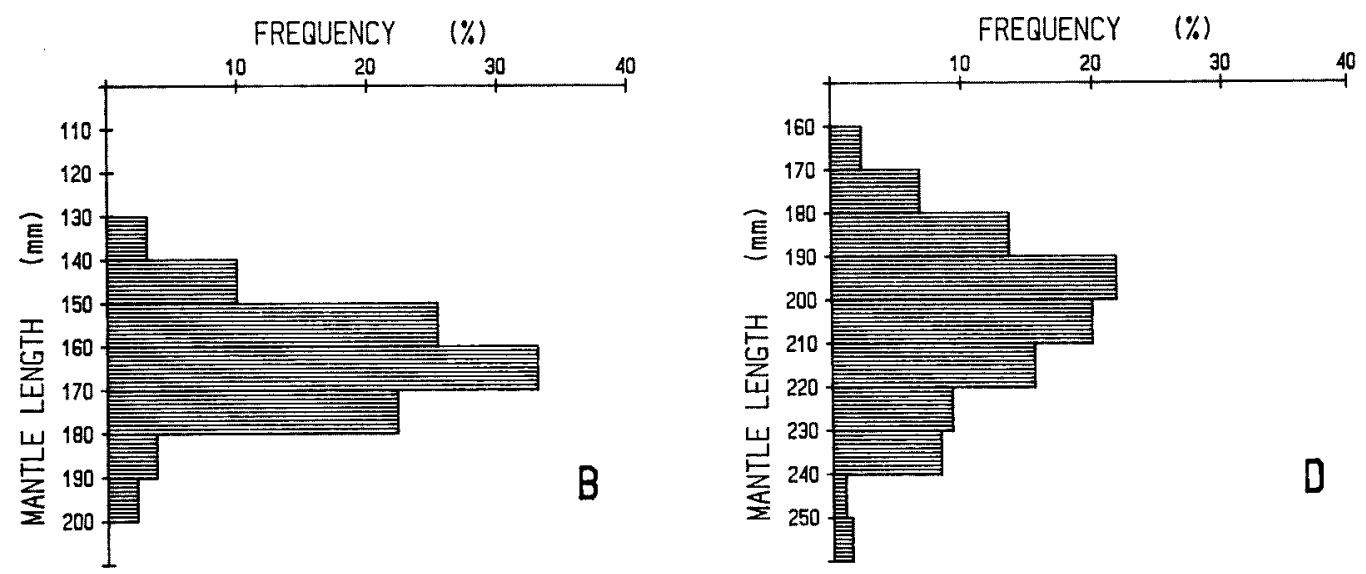

Fig. 2. The mantle length frequency of Sp. 1 (Eucleoteuthis luminosa) and Sp. 2 (Symplectoteuthis oualaniensis) which were caught in the test fishing areas (A: at Kumanonada in wpring, B: at Kumanonada in autumn, C: at Murotooki in autumn, D: at Hyuuganada in autumn).

squids.

\section{Depth of Catching of Squids}

Fig. 6 shows the vertical distribution of water temperature at each of the test fishing area (Kumanonada, Murotooki and Hyuganada). It becomes clear from Fig. 6 that Kumanonada, as compared with the other two areas, is shallower in thermocline and lower in water temperature if the fishing is carried out at particular season.
Hence, the vertical distribution of water temperature differ with fishing areas.

Figs. 7 and 8, show the same correlation between the number of squids caught by depth and measured water temperature. The water temperature was measured at $5 \mathrm{~m}$ depth intervals in all fishing areas and the average temperature was used. In the course of test fishing, no squid was caught at deeper layers of more than $90 \mathrm{~m}$ with the length limit of fishing line. 


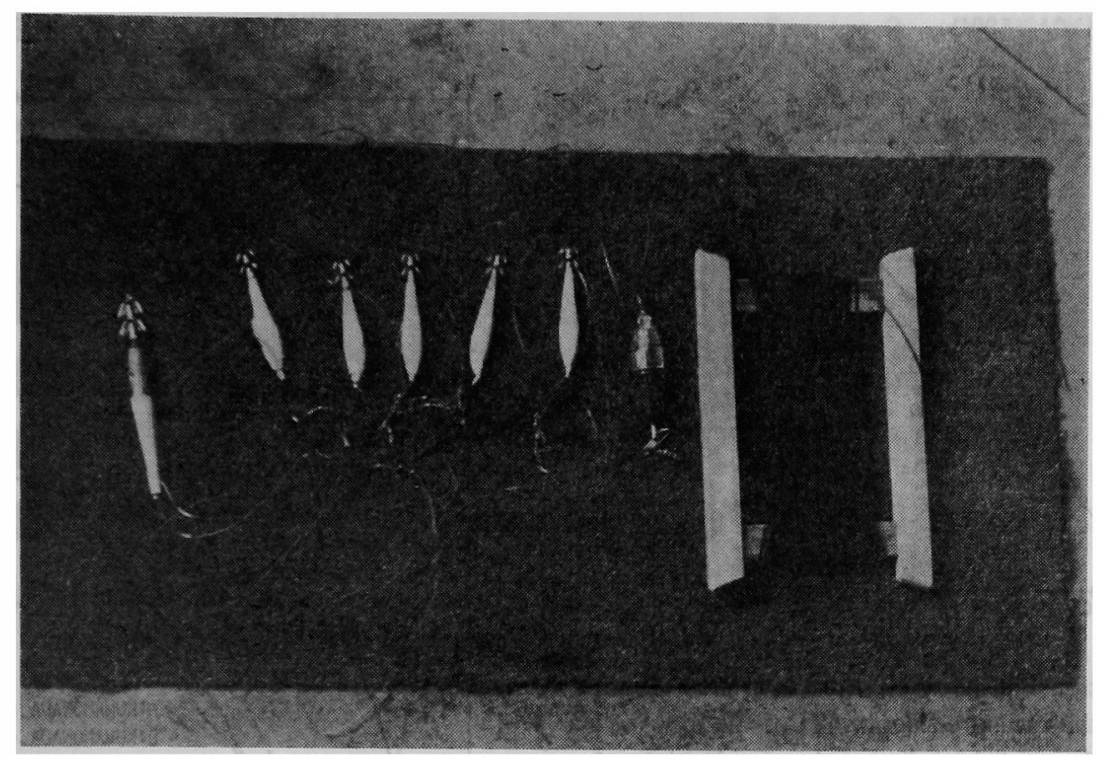

Fig. 3. The photo of the setup of the fishing gear.
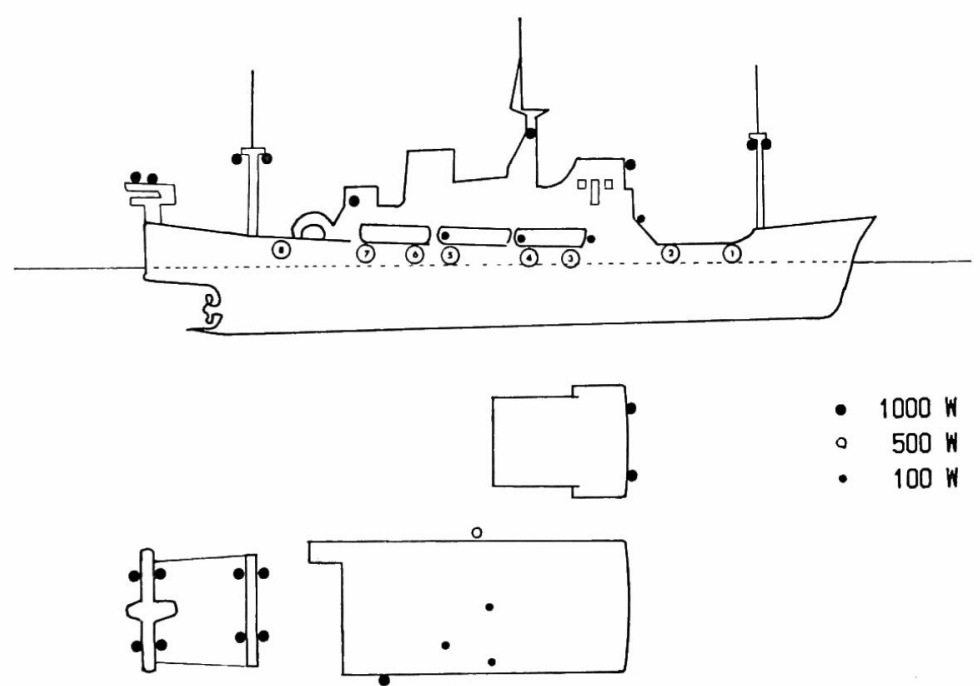

Fig. 4. Location of the illumination lights equipped in the Seisuimaru $(\bullet, 0)$ and the sites of angler (figure).

From Figs. 7 and 8, the following can be pointed out as the characteristics of fishing of the two species under illumination lights.

\section{Symplectoteuthis oualaniensis}

During fishing tests in autumn (Oct.), this species was caught at a depth of $5 \sim 80 \mathrm{~m}$ in each fishing area. The squid schools and were observed at the relatively shallow depth range of $5 \sim$ $40 \mathrm{~m}$ and dense schools were found at the depth of $10 \sim 20 \mathrm{~m}$ in Murotooki area, where the squid catch decreased as the swimming layer increased. The largest catch zone in Hyuganada was 20
$25 \mathrm{~m}$. In two fishing areas, the squid was caught in large quantity at the upper layer above the thermocline at water temperature of $22 \sim 23^{\circ} \mathrm{C}$, while only a small quantity was caught in the other layers.

\section{Eucleoteuthis luminosa}

In Kumanonada, this species was caught at the depth of $5 \sim 70 \mathrm{~m}$ in spring (May). The depth of the large catch zone was $20 \sim 55 \mathrm{~m}$ and the water temperature of this zone was $16 \sim 19^{\circ} \mathrm{C}$. The depth of the largest catch zone was $20 \sim 55 \mathrm{~m}$. In this fishing area, this species was caught at the 


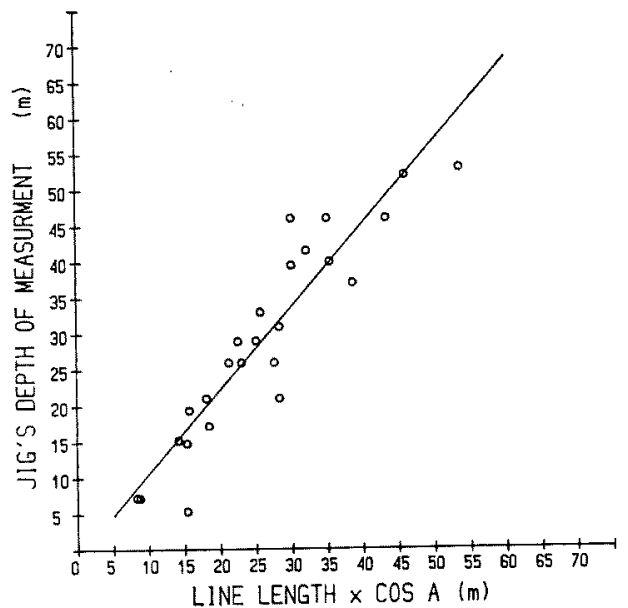

Fig. 5. Relationship between the calculated depth $(\mathrm{X})$ and the measured depth $(\mathrm{Y})$ of the jigs. A: Angle between fishing line and out side plate of ship.

Table 2. Measured values of light quantum $\left(\mu \mathrm{E} / \mathrm{m}^{2} /\right.$ s) ${ }^{* 1}$ at upper $2 \mathrm{~m}$ from sea surface in the night

$\begin{array}{lccccc}\text { Site No. } & 1 & 3 & 6 & 7 & 8 \\ \text { Quantum } & 2.611 & 0.188 & 6.555 & 1.740 & 3.795\end{array}$

*1 $19.5 \mu \mathrm{E} / \mathrm{m}^{2} / \mathrm{s}=1.0 \mathrm{klx}$.

Table 3. Measured values of light quantum $\left(\mu \mathrm{E} / \mathrm{m}^{2}\right)$ s) ${ }^{* 4}$ under a $1000 \mathrm{~W}$ light at site No. 6 in the night

\begin{tabular}{lcc}
\hline \multicolumn{1}{c}{ Depth } & Night & Daytime*3 \\
\hline $2 \mathrm{~m}^{* 1 \mathrm{1}}$ & 6.655 & \\
Surface $^{* 2)}$ & 1.166 & 296.8 \\
$5 \mathrm{~m}$ & 0.380 & 171.4 \\
$10 \mathrm{~m}$ & 0.154 & 147.5 \\
$15 \mathrm{~m}$ & 0.077 & 77.4 \\
$20 \mathrm{~m}$ & 0.041 & 37.4 \\
$25 \mathrm{~m}$ & 0.027 & \\
Transparency & $20 \mathrm{~m}$ & $20 \mathrm{~m}$ \\
\hline
\end{tabular}

*1 Upper $2 \mathrm{~m}$ from sea surface.

* Lower $2 \mathrm{~m}$ from sea surface.

*3 Weather: Overcast cloudy, Sun's altitude $58.8^{\circ}-48.7^{\circ}$.

*4 $19.5 \mu \mathrm{E} / \mathrm{m}^{2} / \mathrm{s}=1.0 \mathrm{klx}$.

depth of $0 \sim 90 \mathrm{~m}$ in autumn (Oct.). The large catch zone differed depending on the time of the fishing tests, but generally the depth was $30 \sim 60 \mathrm{~m}$ and the water temperature was $17 \sim 20^{\circ} \mathrm{C}$. The largest catch zone located at $40 \sim 50 \mathrm{~m}$ depth and its water temperature was $17.8 \sim 19.8^{\circ} \mathrm{C}$. As described above, the catch of $E$. luminosa shows tendency to be large in deeper and lower temperature zone (within thermocline) in comparison with $S$. oualaniensis. There was no correlation between the catching depth and the length of the

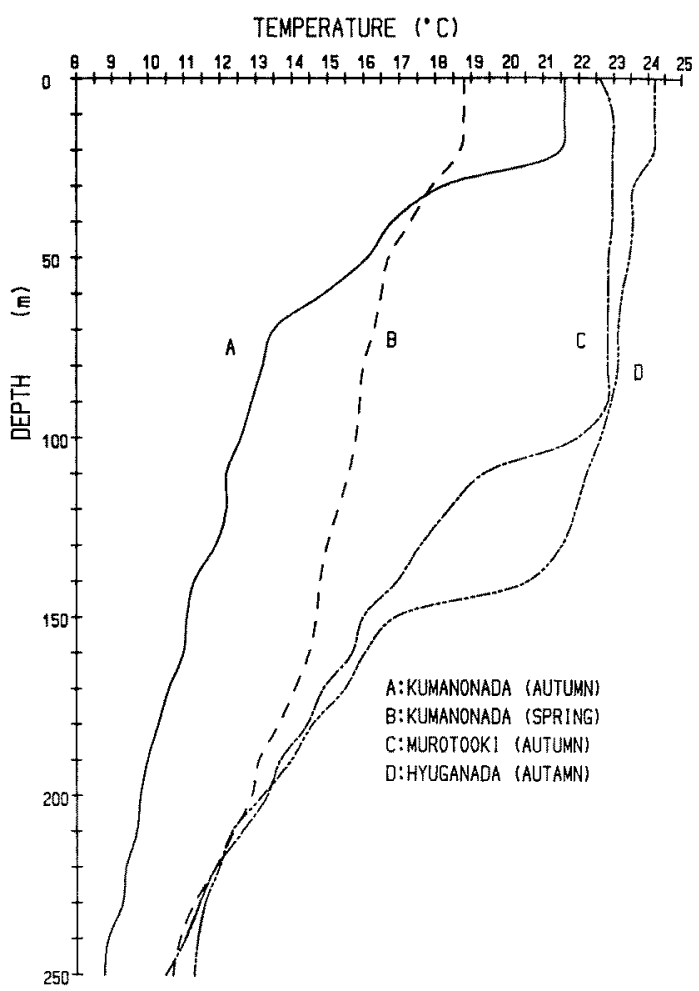

Fig. 6. An example of vertical distribution of water temperature at each of the test fishing area.

mantle of the squids.

The low catch rate was recorded for the two species of squid in autumn (Oct. 14) at Kumanonada (off Owase) as shown in Fig. 9.

The large catch zone of $S$. oualaniensis was shallower $(5 \sim 25 \mathrm{~m})$ than that of E. luminosa, and the water temperature was $19.0 \sim 21.5^{\circ} \mathrm{C}$. As described above, in Kumanonada, $S$. oualaniensis was caught from the oceanic condition which was different from that of Murotooki and Hyuuganada. As compared with E. luminosa, S. oualaniensis appeared to be caught in shallower and higher temperature zone. From the fact stated above, major swimming zone differs from species to species, under illumination lamps. Squids are said to have strong positive photot axis. The result obtained shows that the vertical distribution of the water temperature exerts greater influence on the swimming zone of squids than the illumination intensity in the sea water.

\section{Number of Squids Caught by Color of Jig}

The three ready-made jigs of red, white and green colors were used in experiment. The following precautions were taken in studying the 
Species 2 (MUROTOOKI)

NUMBER OF INDIVIDUAL

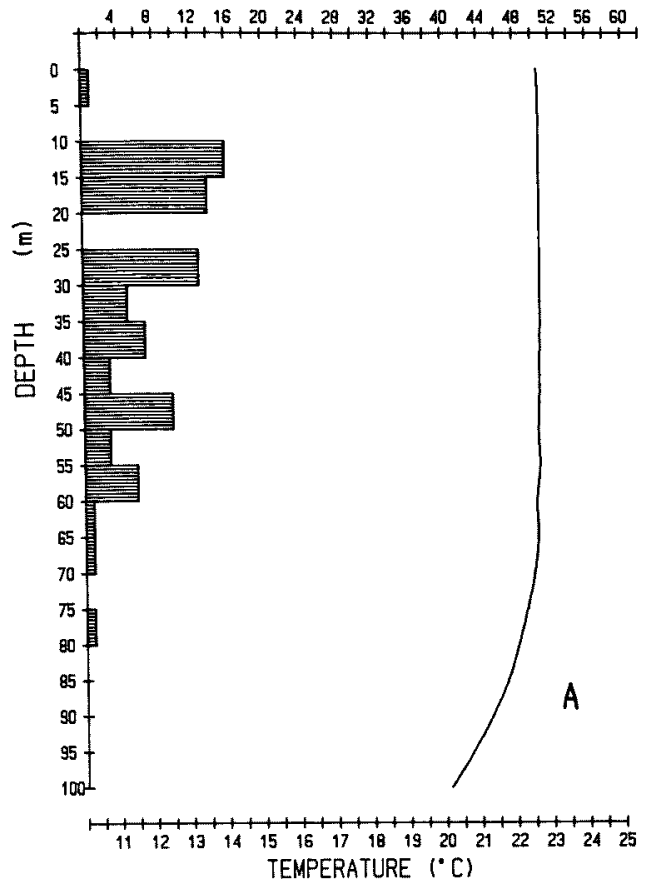

Species 2 (HYUUGAOKI)

NUMBER OF INDIVIDUAL

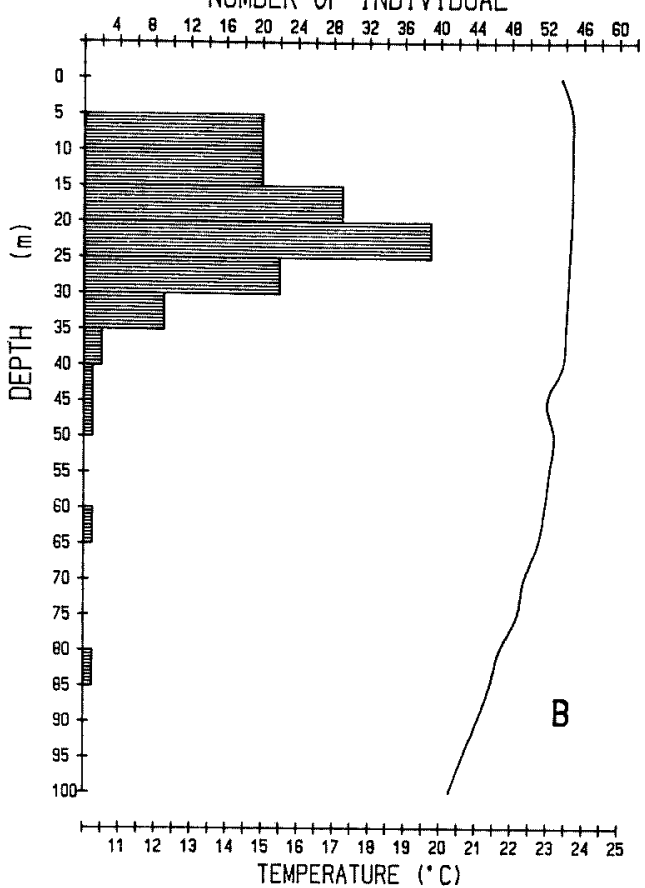

Fig. 7. Correlation between the number of squids ( $S p .2)$ caught by depths and the vertical distribution of water temperature in the fishing areas (A: at Murotooki, B: Hyuuganada).

Species 1 (KUMANONADA)

NUMBER OF INDIVIDUAL

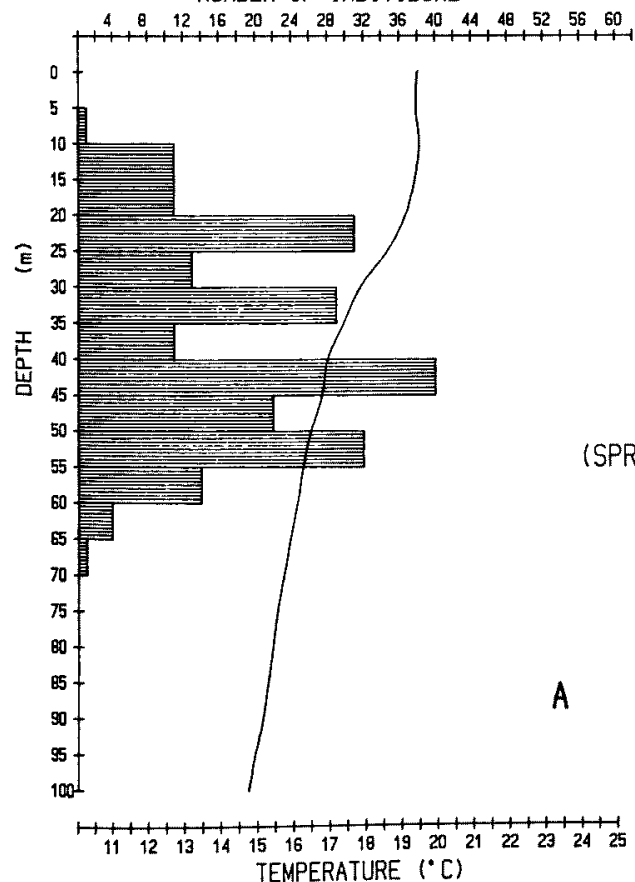

Spesies 1. (KUMANONADA)

NUMBER OF INDIVIDUAL

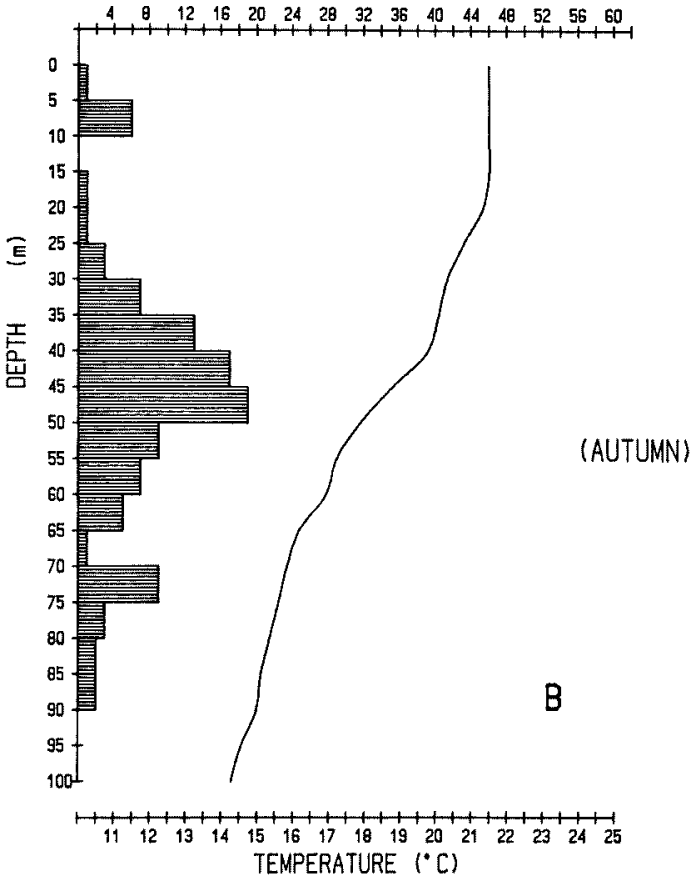

Fig. 8. Correlation between the number of squids ( $\mathrm{Sp} .1$ ) caught by depths and the vertical distribution of water temperature in the fishing areas (A : at Kumanonada in spring, B at Kumanonada in autumn). 

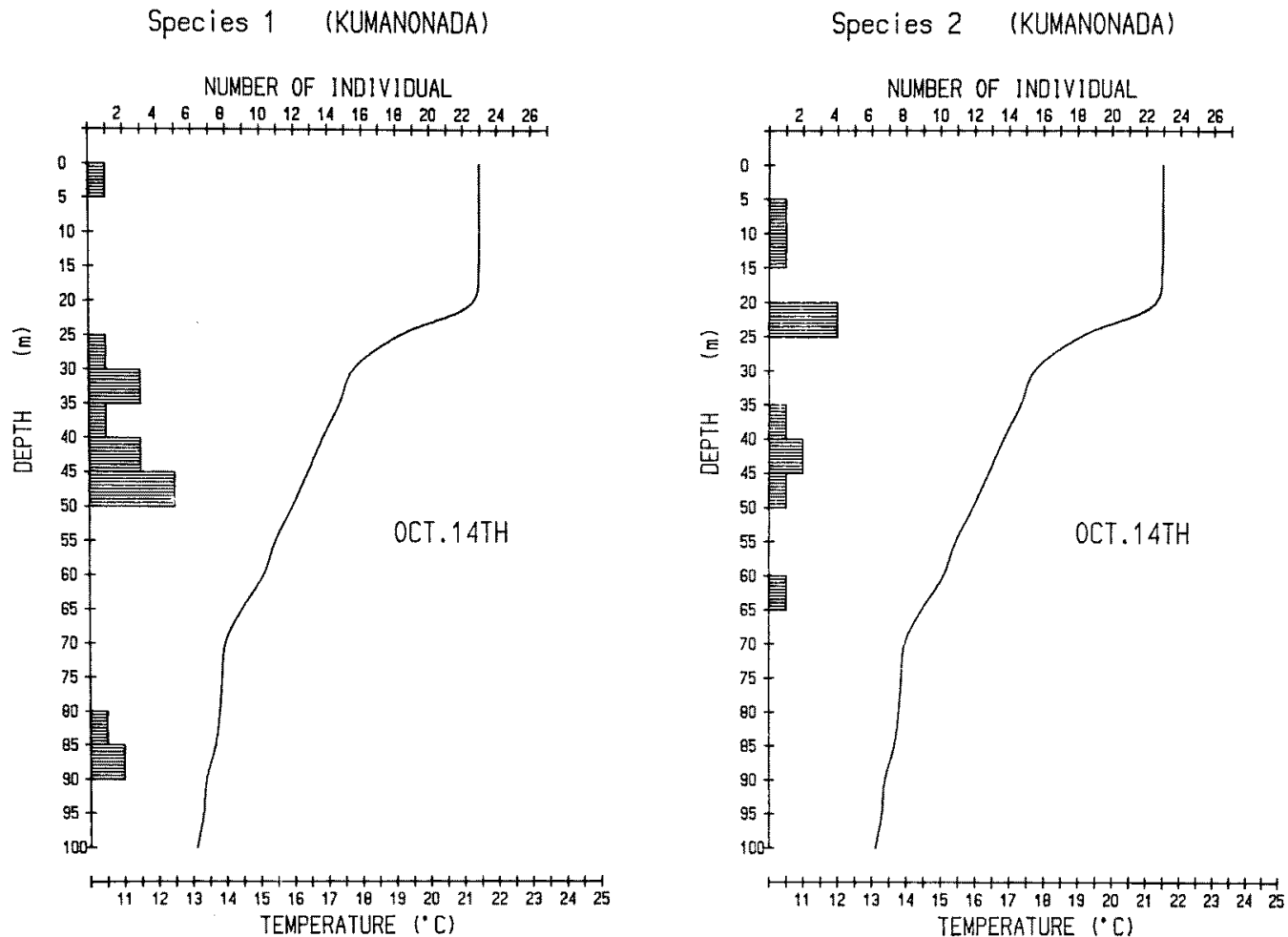

Fig. 9. Correlation between the number of squids (Sp. 1 and Sp. 2) caught by depths and the vertical distribution of water temperature (from mixing layer to thermocline) in autumn (Oct. 14th) at Kumanonada. Sp. 1: Eucleoteuthis luminosa, Sp. 2: Symplectoteuthis oualaniensis.

relationship between the number of squids caught and the color of the jigs. 1: In order to eliminate the effects of the angle's skill and the angling site on the catch, the color of a jig used by an angler and the site of angling of the angler were changed occasionally. 2: Caution was taken so that a particular color of a jig was not used for a longer time than the other colors. 3: Squids caught by the lighted jigs were excluded from the calculation.

During the angling tests, each of the colored jig was used by tow angler every day. The following equation was adopted as a mean of standardizing the daily difference in catch,

Standardized number of caught squids by color of jig $=$ (Number of caught squids by color of jig/number of anglers who used that color) $\times 2$

Table 4 compiles the number of $E$. luminosa and $S$. oualaniensis angled with each of the red, white and green jigs. The chi-squares test was applied to determine whether or not the catch of squids are related to the color of a jig. As a results, the $X^{2}$ value of 3.84 was obtained at a confidence
Table 4. Fishing difference in color of jigs and results of Chi-square tests

\begin{tabular}{lrcl}
\hline \multicolumn{1}{l}{ Species 1 } & & & \\
\hline Colors & Red & White & Green \\
Catches & 118.2 & 111.6 & 112.6 \\
Expected catches & 114.1 & 114.1 & 114.1 \\
Chi-square value & & 0.222 & \\
\hline Species 2 & & & \\
\hline Colors & Red & White & Green \\
Catches & 88.8 & 88.2 & 67.0 \\
Expected catches & 81.3 & 81.3 & 81.3 \\
Chi-square value & & 3.793 & \\
\hline Species 1 and Species 2 & & \\
\hline Colors & Red & White & Green \\
Catches & 207.6 & 199.8 & 179.6 \\
Expected catches & 195.5 & 195.5 & 195.5 \\
Chi-square value & & 2.064 & \\
\hline
\end{tabular}

Sp. 1: Eucleoteuthis luminosa.

Sp. 2: Symplectoteuthis oualaniensis.

level of $95 \%$. Thus, the difference was not statistically significant which means that little difference exists between catch and color of a jig. According to the reports published so far. ${ }^{5)}$ Many 
species of fish have good eyes, and Mugil cephalus, Cyprinus carpio, Zacco platypus, Lateolabrax japonicus and Seriola quinqueradiata, etc., are thought to have excellent sense of color. Generally, such fish live in the surface zone of the water where the illumination intensity is high and thus the sense of color may be required.

As for cephalopoda, the visual sense is said to be developed highly among various sensory organs. The number of the visual cells in squids are 160 thousands, which is nearly equal to that of humans, and their visual sense may be said to be accurate. ${ }^{6)}$ The swimming zone of squids at daytime is a deep where color of water faded to dark blue green color.

At night, squids come to the surface, and the swimming zone has very scant natural light: the environment is almost dark. In view of this fact, it is thought that squids are animals having sharp visual sense which adapted to an environment with very weak light. However, it is hardly thought that they have excellent sense of water.

When considering the habitat of the squids in relation to their sensory organs, the results stated above are useful to the squid fishing with handlines. For obtaining more definite solution, it is absolutely necessary to carry out physiological studies on the visual sense of squids. And it is necessary to perform comparative studies using jigs of every description. In addition, such studies should be carry out observing the scene of angling of squids with a TV camera.

\section{Acknowledgments}

We wish to express our sincere thanks to Captain T. Jinno and crews member of $T / S$ Seisuimaru, Faculty of Bioresources, Mie University. We also thank Mr. K. Tamaki, Mr. C. Moriyama and Mr. M. Matsumoto for their help in collecting the squid samples and arranging of fishing data.

\section{References}

1) M. R. Clarke: Adv. Mar. Biol., 4, 113-116 (1966).

2) E. H. Amaral and H. A. Carr: Mar. Fish. Rev., 42, 51-56 (1980).

3) D. Long and W. F. Rathjen: Mar. Fish Rev., 42, 60-65 (1980).

4) M. Nomura: Saishin Gyogyougijutsu Ippan, 1st ed., Seizando, Tokyo, 1985, pp. 103-108.

5) T. Tamura: Gyorui Seirigaku Gairon, 2 ed., Kouseisha Koseikaku, Tokyo, 1977, pp. 225-228.

6) T. Hara: Tousokurui Moumaku no Kankoushikiso (Koukankaku), Todai Shuppankai, Tokyo, 1975, pp. 53-88. 